\title{
Emission of carbon monoxide, total hydrocarbons and particulate matter during wood combustion in a stove operating under distinct conditions
}

\author{
E.D. Vicente ${ }^{\text {a }}$, M.A. Duarte ${ }^{\text {a }}$, A.I. Calvo ${ }^{\text {b }}$, T.F. Nunes ${ }^{\text {a }}$, L. Tarelho ${ }^{\text {a }}$, C.A. Alves ${ }^{\text {a,* }}$ \\ a Centre for Environmental and Marine Studies, Department of Environment, University of Aveiro, 3810-193 Aveiro, Portugal \\ b Department of Physics, IMARENAB, University of León, 24071 León, Spain
}

\section{A R T I C L E I N F O}

\section{Article history:}

Received 18 July 2014

Received in revised form 28 October 2014

Accepted 13 November 2014

Available online 2 December 2014

\section{Keywords:}

Woodstove

Operating conditions

$\mathrm{CO}$

$\mathrm{PM}_{10}$

Particle size distribution

Emission factors

\begin{abstract}
A B S T R A C T
Wood combustion experiments were carried out to determine the effect of ignition technique, biomass load and cleavage, as well as secondary air supply, on carbon monoxide (CO), total hydrocarbon (THC), particulate matter $\left(\mathrm{PM}_{10}\right)$ and particle number emissions from a woodstove. Wood from two typical tree species in the Iberian Peninsula was selected: pine (Pinus pinaster) and beech (Fagus sylvatica). The highest CO and total hydrocarbon emission factors (EFs) were observed, respectively, for pine and beech, for high and low fuel loads. The highest $\mathrm{PM}_{10} \mathrm{EF}$ was recorded for the operation with low loads for both woods. Secondary air supply produced the lowest $\mathrm{PM}_{10}$ emission factors. The top ignition can decrease the $\mathrm{PM}_{10}$ EF to less than half when compared with the common technique of lighting from the bottom. The lowest particle number emission factors were observed when operating with high loads of split beech logs and when using secondary air supply during the combustion of pine. Regarding particle number distributions, the highest geometric mean diameter (Dg), for both woods, were observed when operating with high loads (with split and non-split wood).
\end{abstract}

(C) 2014 Elsevier B.V. All rights reserved.

\section{Introduction}

Currently, most developed countries are heavily dependent on fossil fuels. In this context, policies that encourage the use of biomass as a renewable energy source are promoted [1,2]. Despite the recognised advantages of the use of biomass, residential wood combustion for heat production has been assessed to be a major source of fine particle mass emissions $[3,4]$ especially during wintertime $[5,6]$. The problems associated with this sector occur particularly during winter, not only for being the period in which residential wood combustion is most commonly used, but also due to weather conditions of stagnation. Thus, residential wood combustion can result in local particulate matter levels comparable to those registered in high traffic areas [7]. Emissions from residential wood combustion are generated only a few metres above the ground; consequently, these emissions have not enough time to dilute, chemically oxidise and react before the population is exposed to them [8].

In Portugal, it is estimated that 2 Mton of wood is annually used in residential combustion, which contributes to particulate emissions representing around $30 \%$ of the total $\mathrm{PM}_{10}$ emitted by the diverse sectors of activity in the country [4].

Airborne particles arising from residential combustion have harmful effects on public health [9-11]. Some studies have been conducted to evaluate the toxicity and mutagenicity of particulate matter resulting

\footnotetext{
* Corresponding author.

E-mail address: celia.alves@ua.pt (C.A. Alves).
}

from domestic biomass combustion [12-14]. Epidemiologic studies have linked fine particulate air pollution with negative health effects like respiratory and heart diseases or even premature dead $[15,16]$. Several studies have shown that the submicrometer sized particles $(<1 \mu \mathrm{m})$ are predominant in PM emissions from this source [17]. The smaller the size of the particle the greater can be the risk for human health. Huang et al. [18] have been following cardiovascular disease patients during two years and observed a reduction in heart rate variability index due to reduced exposure to $\mathrm{PM}_{2.5}$ and black carbon.

Taking into account the impact of these emissions and the need for compliance with legal norms, a rigorous quantification and characterisation of emissions from this sector are necessary. Additionally, and since previous works have suggested that wood and the type of combustion appliance exert a major influence on emissions from this sector [19-24], it is necessary to obtain values for Southern Europe in order to use more representative and specific locally acquired data on emission inventories and source apportionment, photochemistry and climate change models.

The technology used in domestic biomass combustion has a preponderant influence on the observed emission profiles. This is especially evident when emissions from manually and automatically operated systems are compared. Schmidl et al. [24] reported high variability between manual and automatic systems. PM $_{10}$ concentrations obtained by these authors were between 12 and $21 \mathrm{mg} \mathrm{m}^{-3}$ for automatic systems (pellet boilers and pellet stoves) and in the range $111-151 \mathrm{mg} \mathrm{m}^{-3}$ for manually operated systems (typical stove and stove with secondary air intake). Johansson et al. [25] reported emissions 50 times higher in stoves and 
fireplaces compared to more controlled equipment. Johansson et al. [23] observed concentrations of PM in old boilers about 180 times higher than those emitted by modern pellet burners. Schmidl et al. [24] also found variability in the composition of the emitted particles. For manually operated equipment the authors showed that $70 \%$ of the $\mathrm{PM}_{10}$ mass consisted of total carbon (TC). For the automatic combustion equipment, the emitted particles consisted mostly of potassium inorganic salts. Fine et al. [26] reported that 40 to $100 \%$ of the fine particle mass was organic material when a conventional fireplace was used.

Although the emissions from residential wood combustion have been reported in previous studies, there is still a limited understanding of the influence of operating practices on these emissions. They vary considerably among studies, affecting the amount and composition of the flue gas emissions. In addition to batch operation mode and log size, as well as fuel quality and air supply strategies, it is also necessary to take into account that, when studying the effect of practices on emissions, each appliance has its optimal best operating conditions. Different operating practices are also relevant with respect to the effects on human health. Leskinen et al. [27] studied the toxicological responses of the fine particles resulting from three different combustion conditions, namely efficient combustion, intermediate combustion, which simulated improper air staging and partial load, and smouldering combustion. The different combustion efficiencies were simulated in a wood chip grate combustion furnace. In efficient combustion conditions, the emitted fine particles had the highest potential to cause cell death.

The objectives of the work presented here were to identify the influence of operation and real-life conditions on emissions from residential wood combustion. The investigated parameters were: (i) ignition technique (upside-down and bottom-up lighting), (ii) hot start versus cold start, (iii) fuel load and, in the case of high load, degree of cleavage of the logs, and (iv) secondary combustion air supply. This evaluation allows assessing which practices offer the greatest emission reductions and, in consequence, could constitute an important step towards an important reduction of these emissions in South Europe. Moreover, it constitutes an opportunity to characterise more thoroughly the emissions from residential wood combustion by replicating operating conditions commonly carried out in southern European countries and to point out measures that can reduce the emissions from this sector.

\section{Methods}

\subsection{Combustion facility}

The combustion tests were performed with a typical Portuguese stove (power output 9.6-18.2 kW), commonly used for domestic heating, manufactured by Solzaima (Sahara model). The rated output of the stove is $14.0 \mathrm{~kW}$. This equipment is made of stainless steel with a cast iron grate (Fig. 1). The combustion chamber has a volume of $0.093 \mathrm{~m}^{3}$, corresponding to a height of $0.44 \mathrm{~m}$, a width of $0.59 \mathrm{~m}$ and a length of $0.36 \mathrm{~m}$. It is a batch operated furnace with manual control of combustion air; besides performing heating by radiation and natural convection, it has also been designed to include air heating by forced convection.

The combustion air enters the combustion chamber through a regulating device located at the bottom of the equipment, in the ash collection hopper, below the grate of the stove. The flow rate of primary air entering in the combustion chamber was monitored by a mass flow meter (Kurz Model: 500-40 0.0 P-2). This model was designed with built-in inlet piping with the same cross section of the stove's air intake to ensure underneath air flow identical to that originally fed in under the grate. The driving force for the air flow rate throughout the combustion chamber is the natural convection resulting from the up-flowing stream of combustion hot flue gases throughout the chimney. The natural draught mainly depends on flue gas temperature, mass flow and ambient temperature. This fact may cause some variability on the results. It should be noted that the woodstove was operated under similar conditions to those practiced by household users. Contrarily to what happens in Portugal, some other countries adopted regulations, which indicate that the chimney must be able to provide a draught of at least $1.2 \mathrm{~mm}$ water gauge (12 Pa). The stove is equipped with a vertical chimney with an internal diameter of $0.2 \mathrm{~m}$ and $4.0 \mathrm{~m}$ tall, insulated with ceramic fibber (Cerablanket, $128 \mathrm{~kg} \mathrm{~m}^{-3}, 0.025 \mathrm{~m}, 0.23 \mathrm{~W} \mathrm{~m}^{1} \mathrm{~K}^{-1}$ ) in the first $1 \mathrm{~m}$ above the exit of the combustion chamber in order to guarantee operational safety.

The stove was loaded manually by putting each wood batch over the fixed grate installed in the combustion chamber. The grate was placed over a weight sensor (DSEUROPE Model 535QD-A5), which allowed continuous monitoring of the fuel mass during the combustion runs.

The combustion flue gas temperature was monitored using K-type thermocouples at several locations along the system (combustion chamber and chimney). A more detailed description of the combustion facility and appliance can be found elsewhere [28].

\subsection{Combustion procedures and conditions}

The combustion experiments were planned in order to evaluate the influence of the following operating variables: ignition technique (upside-down and bottom-up lighting), fuel load, in the case of high load, split (S) and non-split (NS) logs, and secondary combustion air supply. To investigate the influence of fuel load on flue gas emissions three different conditions were tested: low, medium and high load, according to the fuel weight (Table 1 ). These experiments were initiated by putting a batch of fuel over the bed of hot char from a previous combustion experiment, when the temperature in the combustion chamber was around $100{ }^{\circ} \mathrm{C}\left( \pm 20^{\circ} \mathrm{C}\right)$. All the tests to evaluate the effect of load and log cleavage ( $\mathrm{S}$ and NS logs) on emissions correspond to a condition of "hot start". The wood was cut into logs of $30-40 \mathrm{~cm}$ in length, whether for split or non-split logs. Taking into account that the log size influences the combustion quality, the wood was purchased from a local supplier with a large market share in an attempt of replicating the Portuguese householder's practices. The duration of each combustion cycle depended on the operating condition, load and wood type, ranging from 30 to $95 \mathrm{~min}$. The fuel ignition techniques included the conventional ignition from the bottom and ignition from the top. To initiate the combustion experiments using the bottom-up method of lighting, two pine-cones were kindled with a lighter and the fuel load was put on the very top. The upside-down fire-starting method was achieved using small pieces cut from the same wood being burned and pine-cones cracked on the top of the batch of logs. These experiments were made with wood batches of $2 \mathrm{~kg}$ for both fuels (medium load). The total number of batches for testing each ignition technique was between three and five (Table 1).

To investigate the influence of secondary combustion air supply, experiments were performed using a secondary air inlet $(3.8 \mathrm{~cm}$ internal diameter) at the axial axis of the rear wall of the combustion chamber and located at $16 \mathrm{~cm}$ above the grate of the furnace, in order to promote a secondary combustion zone. The position and dimension of the secondary air supply was defined after discussion with the manufacturer. Secondary combustion air entered the combustion chamber by natural convection as a result of the chimney drag force induced by the up-flowing hot combustion flue gases. The aim was to enhance the mixing between pyrolysis gases from the thermal decomposition of the wood and combustion air, in order to achieve improved burnout.

\subsection{Wood fuel characteristics}

Biofuels were selected from tree species typical of the Iberian Peninsula and commonly used in households for domestic heating: Pinus pinaster (softwood) and Fagus sylvatica (hardwood). The moisture and ash content, together with the elemental composition, are shown in Table 2. The determination of ash and moisture contents was performed in accordance with CEN/TS 14775 and CEN 14774-3, respectively. 


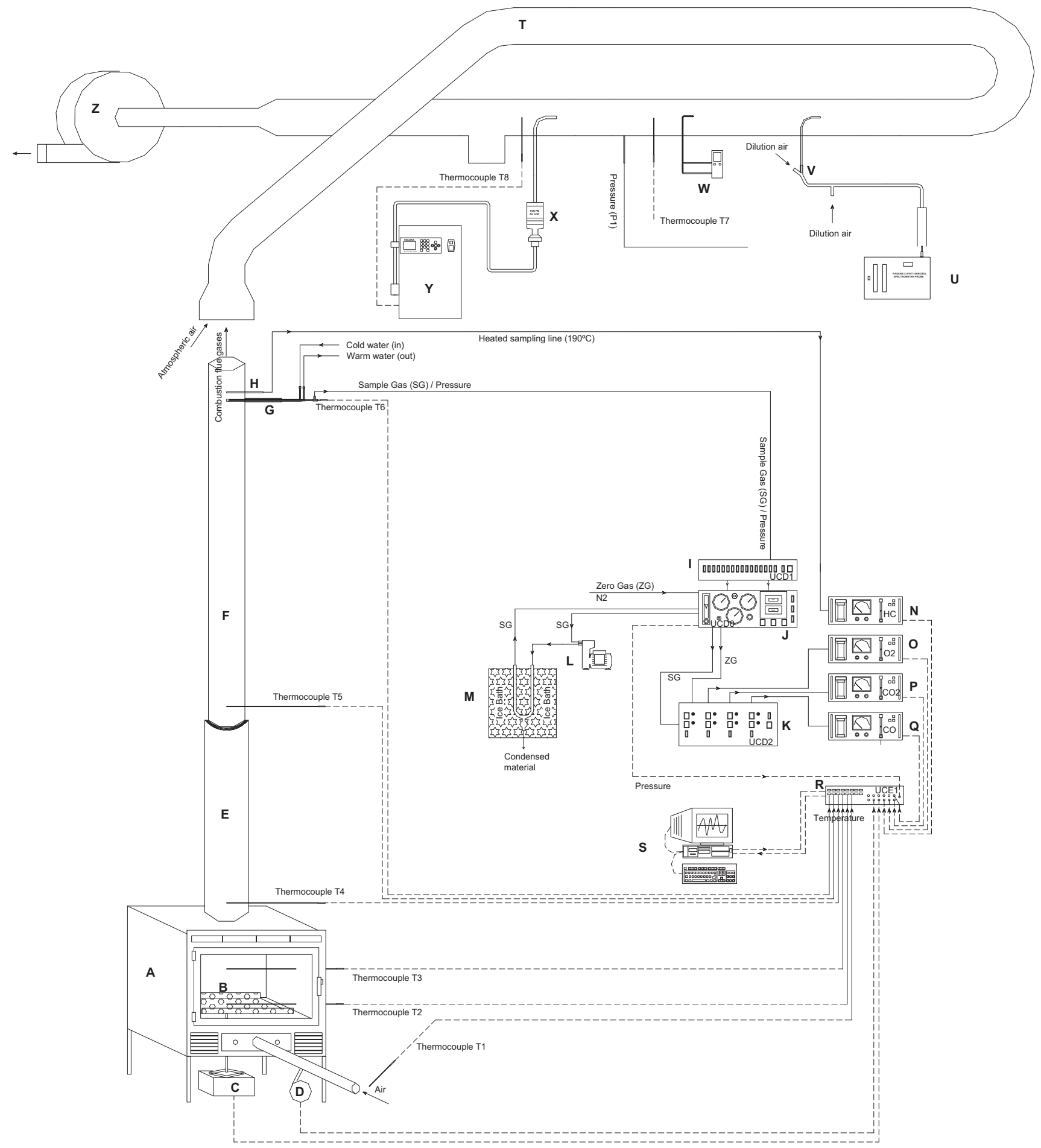

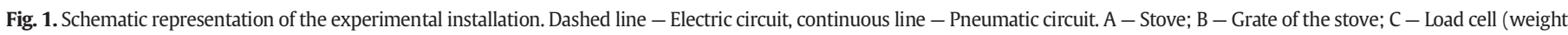

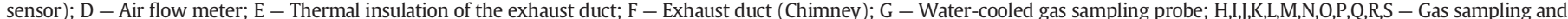

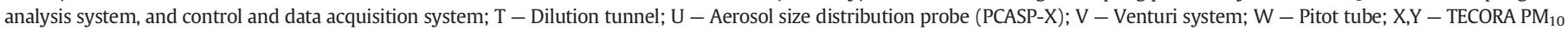
sampling system; Z - Fan.

\subsection{Flue gas monitoring}

The composition of the flue gas was monitored using a system that includes a water-cooled sampling probe, a set of gas conditioning and distribution units, and on-line gas analysers. A sample of the flue gas was dried by condensing the water vapour and other gaseous condensable compounds in an impinger immersed in an ice bath. Then, the dry gas was distributed to a set of on-line gas analysers. The continuous determination of the $\mathrm{O}_{2}$ concentrations was made by a paramagnetic analyser (ADC, O2-700 model, with a Servomex module). $\mathrm{CO}_{2}$ and $\mathrm{CO}$ were monitored by a non-dispersive infrared analyser (Environnement MIR 9000 model). For monitoring total hydrocarbons (THC, expressed 
Table 1

Details of the combustion experiments.

\begin{tabular}{|c|c|c|c|c|c|c|c|}
\hline & Cleavage & Load & $\begin{array}{l}\text { Fuel burnt } \\
(\mathrm{kg})\end{array}$ & $\begin{array}{l}\text { Number of } \\
\text { batches }\end{array}$ & $\begin{array}{l}\text { Flue gas temperature }\left({ }^{\circ} \mathrm{C}\right) \text { in the } \\
\text { combustion chamber }\end{array}$ & $\begin{array}{l}\text { Flue gas temperature }\left({ }^{\circ} \mathrm{C}\right) \text { at the } \\
\text { chimney exit }\end{array}$ & $\begin{array}{l}\text { Rate of fuel conversion } \\
\left(\mathrm{kg} \cdot \mathrm{h}^{-1}\right)\end{array}$ \\
\hline \multirow[t]{7}{*}{ Pinus pinaster } & \multirow[t]{6}{*}{ Split } & Low load & $1.0-1.2$ & 5 & $284 \pm 41$ & $135 \pm 20$ & $1.22 \pm 0.17$ \\
\hline & & Medium load & $1.9-2.1$ & 5 & $358 \pm 36$ & $164 \pm 12$ & $1.87 \pm 0.38$ \\
\hline & & High load & $3.7-4.1$ & 3 & $417 \pm 36$ & $205 \pm 18$ & $3.30 \pm 0.55$ \\
\hline & & Secondary combustion air & $2.2-2.8$ & 5 & $421 \pm 51$ & $366 \pm 26$ & $2.51 \pm 0.42$ \\
\hline & & Bottom-up ignition & $1.9-2.1$ & 4 & $329 \pm 48$ & $151 \pm 18$ & $2.25 \pm 0.18$ \\
\hline & & Top-down ignition & $2.1-2.2$ & 3 & $356 \pm 18$ & $163 \pm 7$ & $2.31 \pm 0.20$ \\
\hline & Non-split & High load & $3.9-4.0$ & 3 & $393 \pm 83$ & $180 \pm 18$ & $2.43 \pm 0.05$ \\
\hline \multirow[t]{6}{*}{ Fagus sylvatica } & \multirow[t]{5}{*}{ Split } & Low load & $1.0-1.2$ & 3 & $252 \pm 9$ & $113 \pm 10$ & $1.12 \pm 0.06$ \\
\hline & & Medium load & $1.8-2.1$ & 3 & $412 \pm 27$ & $185 \pm 2$ & $2.38 \pm 0.07$ \\
\hline & & High load & $3.8-3.9$ & 3 & $440 \pm 51$ & $216 \pm 13$ & $3.32 \pm 0.52$ \\
\hline & & Bottom-up ignition & $1.8-2.0$ & 4 & $362 \pm 42$ & $167 \pm 17$ & $2.78 \pm 0.13$ \\
\hline & & Top-down ignition & $1.8-1.9$ & 3 & $350 \pm 36$ & $149 \pm 10$ & $2.13 \pm 0.34$ \\
\hline & Non-split & High load & $3.8-3.9$ & 3 & $413 \pm 2$ & $202 \pm 8$ & $2.80 \pm 0.09$ \\
\hline
\end{tabular}

as $\mathrm{CH}_{4}$ ), a heated probe and sampling line (at $180^{\circ} \mathrm{C}$ ) were used together with an analyser with flame ionisation detector (Dyna-FID, model SE310).

\subsection{Particle measurement}

Sampling of particulate matter with aerodynamic diameters below $10 \mu \mathrm{m}\left(\mathrm{PM}_{10}\right)$ was performed in a dilution tunnel installed downstream of the chimney under isokinetic conditions. The entrance of the flue gas into the dilution tunnel is made by suction and, for this purpose, the input of the dilution tunnel is wider than the output of the chimney. This configuration simultaneously promotes dilution and effective mixing due to the turbulence generated [24]. The dilution of the flue gas to sample the exhaust particles is widely used [17,21,29-33] since it allows the simulation of the rapid cooling and mixing that occurs when the exhaust gases are released into the atmosphere. With this aim, the inlet of the dilution air (ambient air) takes place at the exit of the chimney. The dilution tunnel has $0.20 \mathrm{~m}$ internal diameter, and a length of $11 \mathrm{~m}$. The particulate matter sampling point was located at $10 \mathrm{~m}$ downstream the dilution tunnel entrance. The sampling train included a specific sampling head $\left(\mathrm{PM}_{10}\right)$, a pump, and a control and data acquisition system, all part of a TCR TECORA (model 2.004.01) instrument. The equipment has been operated at a flow of $2.3 \mathrm{~m}^{3} \mathrm{~h}^{-1}$ onto quartz filters (47 $\mathrm{mm}$ diameter). To ensure sampling under isokinetic conditions a stainless steel probe with an internal diameter of $11 \mathrm{~mm}$ was used. Two consecutive filters were collected during each combustion test. Since the replacement took less than $1 \mathrm{~min}$, the overall particle emission factor for each combustion cycle was considered not to be significantly affected. The temperature in the particle sampling point was in the range $25-35^{\circ} \mathrm{C}$, and the relative pressure was typically at 98.1 Pa below the atmospheric pressure. The volumetric gas flow rate throughout the tunnel, and respective combustion gas dilution ratio were calculated from the mean gas velocity in the cross section of the dilution tunnel. This mean gas velocity was estimated from

Table 2

Moisture, ash and elemental composition of the wood used as fuel in the combustion experiments.

\begin{tabular}{lll}
\hline & Pinus pinaster & Fagus sylvatica \\
\hline $\begin{array}{l}\text { (wt.\%, as received) } \\
\text { Moisture }\end{array}$ & 9.90 & 9.60 \\
(wt.\%, dry basis) & & \\
Ash & 0.40 & 1.80 \\
C & 51.40 & 47.97 \\
H & 6.20 & 6.26 \\
N & 0.16 & 0.04 \\
S & bdl* & bdl* \\
O** & 41.84 & 43.93 \\
\hline
\end{tabular}

*below detection limit of 0.01 wt.\%; **by difference. the differential pressure monitored by a Pitot tube and respective pressure sensor (Testo AG 808) and a K-type thermocouple [29,34]. The gas flow velocity was $6.3 \pm 0.1 \mathrm{~m} \mathrm{~s}^{-1}$ and the dilution ratios applied to the flue gases from the woodstove were around 25:1. The volumetric flow ratio was obtained by multiplying the flue gas velocity by the cross section of the dilution tunnel. The dilution factor was estimated by dividing the flow rate in the dilution tunnel by the flow of exhaust gases.

After each combustion experiment, the $\mathrm{PM}_{10}$ sampling head was cleaned to minimise contamination of the subsequent experiments. Background samples were collected to assess any contamination arising from the dilution air. The average of several blanks was subtracted from measured values.

Gravimetric analysis was performed with a microbalance (RADWAG $5 / 2 \mathrm{Y} / \mathrm{F}$ with an accuracy of $1 \mu \mathrm{g}$ after $48 \mathrm{~h}$ equilibration in a room with controlled temperature and humidity. Quartz fibre filters used in this work were ignited at $500{ }^{\circ} \mathrm{C}$ for $6 \mathrm{~h}$ to eliminate organic contaminants before sampling. The baked filters require a more careful storage, as easily absorb gaseous organic compounds and/or carbon dioxide from the environment in substantial quantities [35]. Thus, in order to avoid contact with sources of contamination, exposure to ambient air after calcination was avoided, keeping the filters in petri dishes. The transport and storage were carried out in a desiccator. Filter weight was obtained from the average of six measurements, when the variations were less than $0.02 \%$.

The particle number concentrations and particle number size distributions are also important parameters to develop a quantitative assessment of their impacts on both human health and the environment. The particle number size distributions were measured with a laser spectrometer (Passive Cavity Aerosol Spectrometer Probe, PMS Model PCASP-X) in a second dilution tunnel with an internal diameter of $0.07 \mathrm{~m}$ and $1.56 \mathrm{~m}$ length. The device measures the size distribution of latex particles with nominal optical diameters between 0.1 and $10 \mu \mathrm{m}$ in 31 discrete channels. To obtain the exact number concentration of particles in each channel it is necessary to made several corrections to the spectrometer counts [36]. Since the optical particle counter was calibrated with latex particles with a refractive index of $1.58-0.0 \mathrm{i}$, it is necessary to make the refractive index correction for the aerosol sampled. The correction of the raw size bins in order to obtain the exact number concentration versus exact size was done using a programme based on the Mie Theory. The refractive index is a parameter used to describe the scattering and absorption characteristics of a particle. Different methodologies have been proposed to estimate the particle refractive index [37-39]. Due to the lack of information on optical properties of the sampled particles, the methodology proposed by Levin et al. [39] seemed to be the most suitable, since it was intended to estimate the refractive index of particles from their chemical composition, assuming that the $\mathrm{PM}_{10}$ constituents are present in the form of certain chemical compounds, having a specific density and typical refractive index. Since it was found that carbonaceous constituents accounted for the largest 
particle mass fraction (42-96\%), the refractive index was estimated based on these compounds. It was also necessary to make the adjustment of the sample volume according to the altitude of the sampling point. This correction was made as recommended by the manufacturer.

\section{Results and discussion}

\subsection{Combustion conditions}

For each combustion test, the continuous monitoring of the following parameters was performed: 1) fuel load on the grate, 2) combustion air flow rate entering the combustion chamber, 3 ) temperature of the exhaust gas in the combustion chamber and in the chimney, and 4) $\mathrm{O}_{2}, \mathrm{CO}_{2}$, $\mathrm{CO}$ and THC concentrations.

The combustion cycles were characterised by three main stages, namely ignition, flaming and smouldering. The first stage corresponds to the heating of the biomass followed by drying and initial steps of devolatilisation, without the existence of visible flame. This initial stage of combustion is a critical step, since the fast devolatilisation of the fuel originates high amounts of $\mathrm{CO}$ and THC in a short time. These compounds are not oxidised, despite the high concentration of $\mathrm{O}_{2}$ available. This can be explained by the low temperatures in the combustion chamber and poor mixing between the combustion air and flue gas. As long as the $\mathrm{O}_{2}$ concentrations are too high and the temperatures in the combustion chamber are too low to achieve appropriate burnout conditions, high $\mathrm{CO}$ and THC concentrations in the flue gas are detected. The flaming stage is characterised by devolatilisation and combustion of volatiles and char during which a vigorous flame is observed. In this stage the $\mathrm{O}_{2}$ availability in the flue gas and sufficiently high temperatures in the combustion chamber provide acceptable burnout conditions. During this phase, the oxygen concentration in the flue gases decreases rapidly, as well as the THC and CO concentrations. On the other hand, the $\mathrm{CO}_{2}$ concentration in the flue gas increases due to the oxidation of volatiles (Fig. 2). At the end of the combustion cycle, char combustion takes place. In the smouldering stage, the $\mathrm{O}_{2}$ concentrations in the flue gas start to increase and the temperatures in the combustion chamber decrease again. Consequently, the burnout quality decreases and the $\mathrm{CO}$ emissions increase. Small-scale combustion appliances use natural draught. Therefore, in the ignition phase and initial steps of devolatilisation, large amounts of $\mathrm{CO}$ and $\mathrm{HC}$ are formed, but the draught of air is scarce. During the main combustion stage, when the draught of air is large enough, the devolatilised gases are oxidised. If the draught is too strong, i.e. if the combustion rate is too high, the devolatilised gases could go directly through the chimney without reacting, due to insufficient residence time in the combustion chamber [40]. Thus, two periods of high CO and THC levels were identified in the

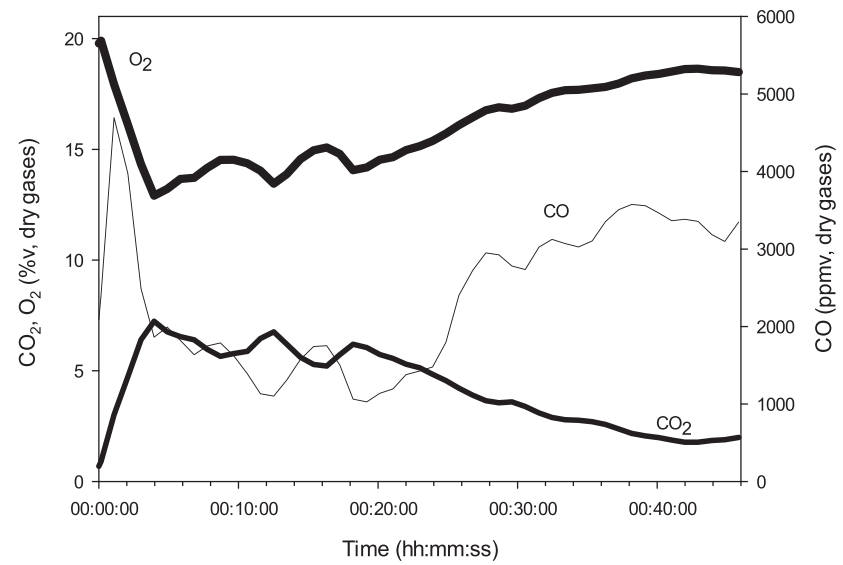

Fig. 2. Evolution of the $\mathrm{O}_{2}, \mathrm{CO}_{2}$ and $\mathrm{CO}$ concentration in the flue gas at the chimney exit during the combustion of a batch of fuel operating with medium load and using wood from pine as fuel. present work and in other studies [28]: a first peak related to the fuel fast devolatilisation after reloading the combustion chamber and a second peak related to the char combustion at relatively low temperatures $\left(<500{ }^{\circ} \mathrm{C}\right)$.

The maximum $\mathrm{CO}$ concentrations for the combustion of pine occurred during the operation with high fuel load using split (7546 ppmv, dry gases) and non-split logs (7661 ppmv, dry gases). The combustion of beech showed the same trend, also with high values during the operation with high loads of both split (8045 ppmv, dry gases) and non-split logs (7411 ppmv, dry gases). The maximum THC concentrations were also recorded under the same operating conditions: $3401 \mathrm{ppmv}$ (wet gases) for pine and $4031 \mathrm{ppmv}$ (wet gases) for beech. The fuel load had a clear effect on emissions. The use of high loads, with and without cleavage, may lead to incomplete combustion due to the insufficient combustion air supply and poor mixing between the combustion air and flue gas.

Regarding the evolution of the combustion air flow admitted to the combustion chamber during a combustion cycle, there is a sudden increase during the first few minutes (5-10 min), until it reaches its maximum value and then decreases gradually until the end of the test (Figs. 3 and 4).

When air staging was tested, it was observed that the primary combustion air flow was the lowest among all the tests performed. The flow rate maximum value ranged between 32 and $34 \mathrm{Nm}^{3} \mathrm{~h}^{-1}$. The air staging enables to reduce the combustion air supplied directly to the fuel bed, i.e., the flow of primary combustion air. Reducing the primary combustion air allows to keep the temperatures in the combustion chamber on a moderate level. Maintaining the same overall combustion air ratio allows to use reduced amounts of primary combustion air, which results in higher amounts of secondary combustion air entering the combustion chamber and, therefore, higher turbulence and an improved mixing [41].

With respect to biomass consumption, it was possible to distinguish two phases. In the first one, a high fuel consumption rate was observed, which graphically is consonant with an accentuated slope (Figs. 3 and 4). In the second phase a slow loss of mass over time was registered, which corresponds to the smouldering stage of the combustion cycle. For medium load combustion conditions, it seems that the first phase occurred during the first $30 \mathrm{~min}$ and the second phase from this moment until the end of the combustion cycle. The duration of both phases of fuel consumption is related to the duration of the entire combustion cycle, which in turn is a function of the fuel loading. A direct relationship between temperature in the combustion chamber and combustion air flow rate was observed. When the air flow rate entering the combustion chamber was higher, the duration of the combustion cycle was shorter. The highest temperatures were reached under the operation with high loads, whilst the lowest temperatures were observed for the operation with low

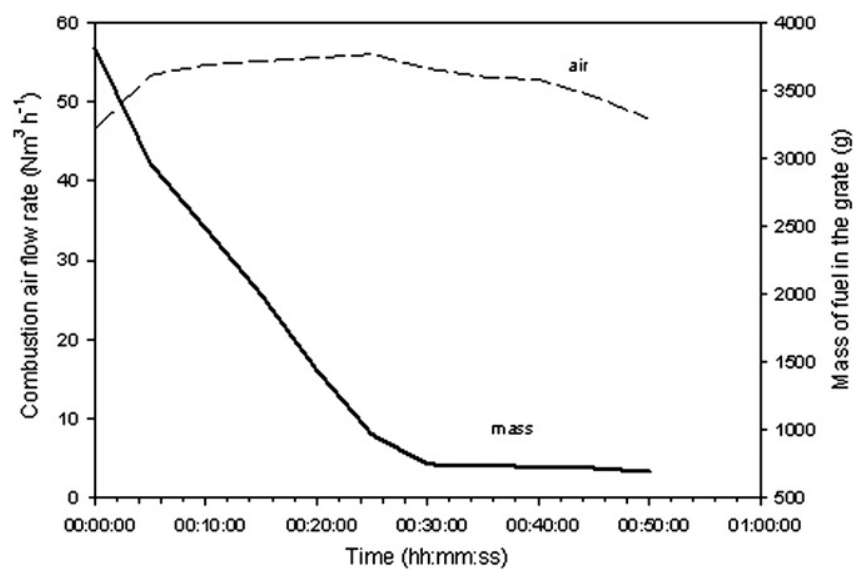

Fig. 3. Evolution of the fuel weight in the grate and the air flow rate entering the combustion chamber during the combustion of a batch of fuel operating with high load (S) using wood from pine as fuel. 


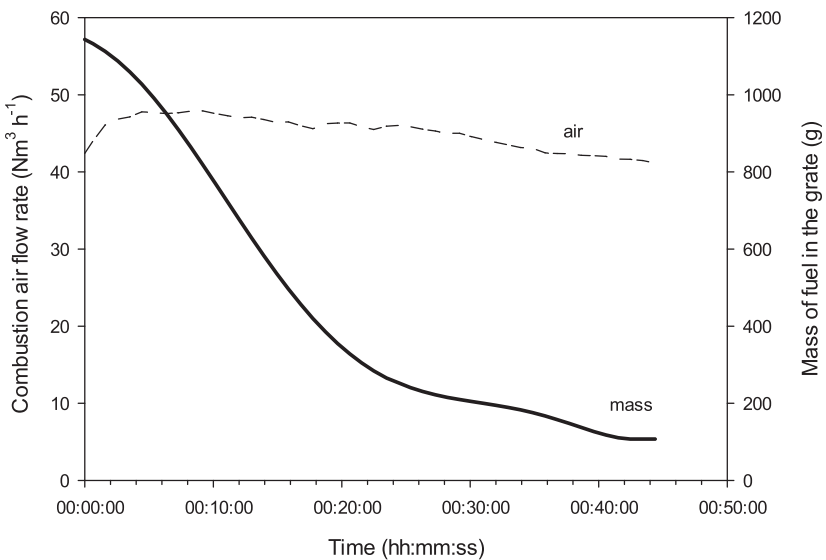

Fig. 4. Evolution of the fuel weight in the grate and the air flow rate entering the combustion chamber during the combustion of a batch of fuel operating with low load using pine as fuel.

loads (Table 1). The highest fuel rate conversion was observed for the operation with high load (S) for both fuels, whilst the lowest was recorded for operation with low load (Table 1). For the operation with medium loads (with and without secondary air supply), the combustion cycles lasted approximately $60 \mathrm{~min}$. Contrary to the conditions of medium loads, for which the duration of a cycle is very similar between batches, the combustion cycles with low and high fuel loads showed highly variable durations. This variability results in different fuel conversion rates and thus different durations of the first and second phases of biomass consumption. The variability observed may be related to operational problems arising from the use of too low or high loads. Low fuel loads have contributed to lower combustion temperatures and reduced char beds, causing difficulties on the ignition of the next fuel batch (combustion chamber recharge). Thus, it is generally observed that during the first refuelling after heating the chamber with a medium load of fuel, temperatures were moderate in the chamber, ignition occurred easily, and the cycle presented a short duration (about 30 min). In subsequent batches, ignition was delayed, since the bed of hot coal was reduced, and the cycle took twice as much time. However, after performing multiple batches, the temperature rose whether in the combustion chamber or in the char bed. For high fuel loads, the combustion cycles lasted from 40 to $80 \mathrm{~min}$. When the firebox is highly loaded with finely split pieces of wood, excessive compaction may occur. Because the combustion air cannot reach all the pieces, full ignition may be delayed. On the other hand, in the tests where no cleavage was applied to the logs, difficulties in lighting the fire were again felt and low fuel consumption rates were observed. Larger pieces make it difficult to ignite because they have larger surface areas, making them tougher to catch fire.

The use of different ignition techniques produced no significant effects whether on the combustion air inlet or on the biomass consumption. Since the load used to start-up the fires is equivalent to those used for evaluating the emissions of medium fuel loads, the air inlet and biomass consumption profiles are quite similar in both cases. However, it is necessary to take into account that the cold start involves lower temperatures and, consequently, lower combustion air flows at the beginning of the combustion cycle. Comparing the average combustion air flow for the hot start-up (medium load) and cold start-up experiments, only slight differences were observed (about $1 \mathrm{Nm}^{3} \mathrm{~h}^{-1}$ higher when initiating hot start-up combustion tests).

\subsection{Gaseous emissions}

The emission factors were calculated following the methodology described by Calvo et al. [28], taking into account the concentration of the compound in the flue gas, the mean combustion gas flow rate in the chimney, the sampling time and the fuel mass consumed (dry basis). Fig. 5 displays $\mathrm{CO}$ and THC emission factors, for pine and beech combustion, obtained for each condition tested. The highest $\mathrm{CO}$ emission factor ( $73.9 \mathrm{~g} \mathrm{~kg}^{-1}$ of wood burned, dry basis) for pine occurred when the combustion at high load conditions with non-split logs was carried out. Paired $t$-tests indicate no statistical difference $(\alpha=0.05)$ between medium load and either high ( $S$ and NS) or low loads. However, the difference between split and non-split high loads was statistically significant ( $p=0.037$ ). For beech, the condition that produced the highest $\mathrm{CO}$ emission factor ( $72.6 \mathrm{~g} \mathrm{~kg}^{-1}$ of wood burned, dry basis) was the low fuel load. The difference between the medium load and the low load was statistically significant $(p=0.0233)$. The paired $t$-tests performed with the mean $\mathrm{CO}$ emission factors of high loads ( $\mathrm{S}$ and NS) indicated no statistical difference ( $\alpha=0.05)$. As regards the ignition technique (from the bottom and from the top), for beech combustion, the $p$ value revealed that there is a significant difference between the two means $(p=0.0036)$. Similarly to CO, the highest THC emission factor for pine combustion occurred for high load conditions without cleavage ( $9.0 \mathrm{~g} \mathrm{~kg}^{-1}$ of wood burned, dry gases). The difference observed between medium and high load (NS) is statistically significant $(p=0.0063)$. The difference observed between operation with medium loads and operation with secondary air supply was also found to be statistically significant $(p=0.0051)$. For beech combustion, the condition that generated the highest THC emission factor was low load (10.7 $\mathrm{g} \mathrm{kg}^{-1}$ of wood burned, dry gases). The difference in the THC emission factor between the operation with medium and low loads was found to be statistically significant $(p=0.0012)$. The paired $t$-tests performed with high loads ( $\mathrm{S}$ and NS) indicated no statistical difference $(\alpha=0.05$ ). The use of high loads, with and without cleavage of the logs, may lead to incomplete combustion. This occurs because a large fuel batch increases the rate of devolatilisation of the fuel, which causes an insufficiency on the combustion air supply [8]. In equipment with no secondary combustion chamber, the load is a critical aspect, since the empty space in the upper part of the chamber acts as a secondary combustion chamber. When using an excessively high fuel load this space is reduced and consequently the residence time is not enough for mixture of the flue gas with combustion air and gas phase oxidation to occur [42]. The CO and THC emission factors obtained in the present work for beech combustion under medium load conditions are in general agreement with the values presented by Evtyugina et al. [43] for the same wood fuel and combustion appliance. Amorim et al. [44] assessed, among other variables, the influence of biomass size and combustion air flow rate on gaseous emission factors. The statistical analysis performed by the authors revealed that the most influential parameter was the biomass size. The $\mathrm{CO}_{2}$ emission factors were higher when using biomass with smaller diameter. Conversely, the $\mathrm{CO}$ and $\mathrm{CH}_{4}$ emission factors were higher when combusting with larger log sizes. This trend was also observed in this study. The emission factors presented by Amorim et al. [44] are close to the values obtained in the present study for beech combustion. The lower emissions of incomplete combustion products when using smaller pieces result from the fact that they produce a longer flame combustion phase and a shorter smouldering phase. Hytönen \& Jokiniemi [40] conducted tests in a combustion stove with primary and secondary air inlet. The tests evaluated the influence of moisture content (10 to $25 \%$ ), fuel load (1, 2 and $3 \mathrm{~kg}$ ), and degree of cleavage. They found that the emissions cannot be reduced, even by modifying the air combustion flow, if a low fuel load is used. In these conditions, the combustion intensity was low, not allowing the mixing of the flue gases and combustion air. At high loads, they observed high combustion rates, making it possible to obtain an adequate mixing degree, although combustion air needs have been high. The highest degree of cleavage (over $30 \%$ of surface area) and lower moisture content generated greater CO emissions for high fuel loads. When applying a high degree of cleavage at low loads and increased moisture content, a reduction in emissions was observed. The explanation lies in the fact that, when the reaction area is high and the moisture content is much reduced, the combustion is more intense and can lead to local conditions of 


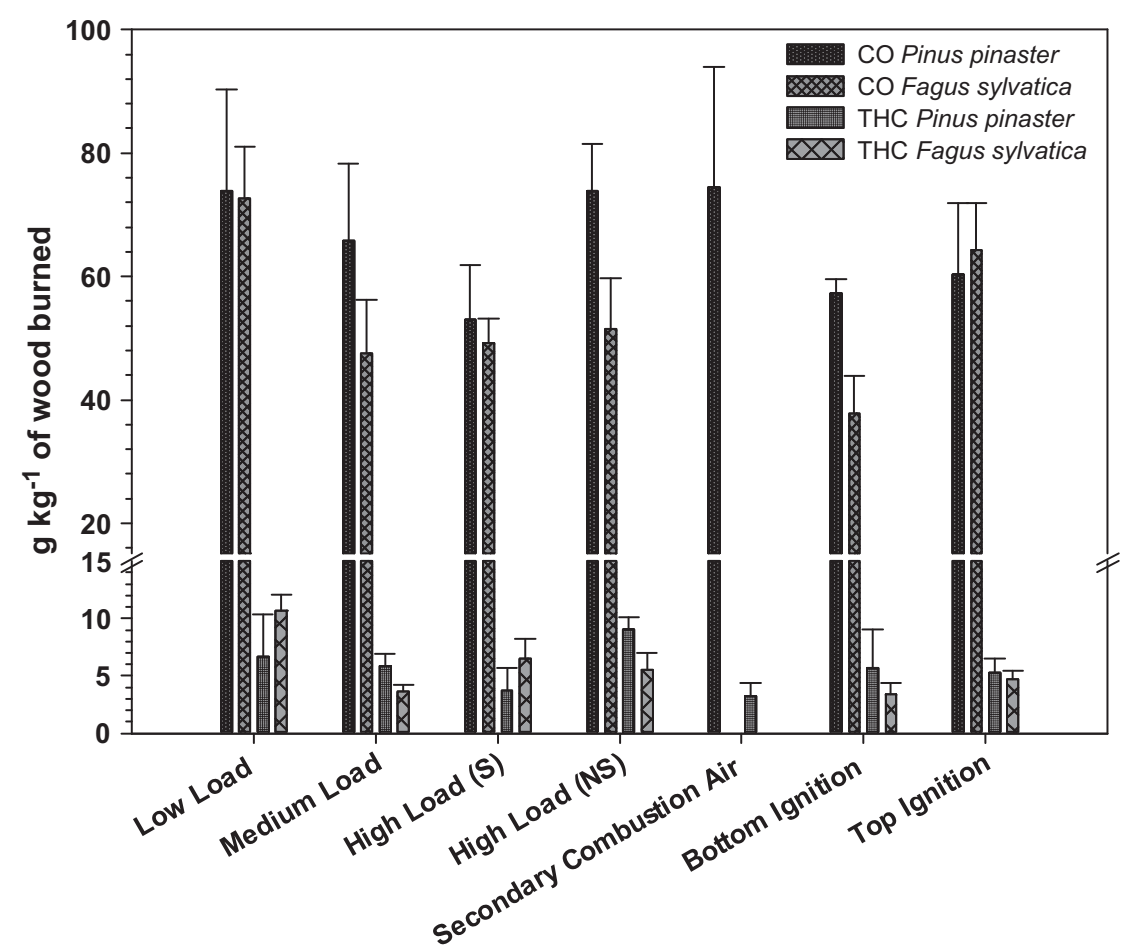

Fig. 5. Average and standard deviations of $\mathrm{CO}$ and THC emission factors ( $\mathrm{g} \mathrm{kg}^{-1}$ wood burned, dry basis).

oxygen deficit. The high moisture content controls the combustion rates, producing lower emissions of unburned products.

In the kind of appliance used in the present work, all the combustion air is supplied as primary air under the grate of the fixed bed. The secondary inlet allows the supply of secondary air over the firewood batch and, consequently, an improved combustion of the devolatilised gases, leading to lower emissions compared to those of the appliance with the traditional design.

Only a slight reduction in the THC emission factor was observed when using the secondary air inlet. This may have to do with the fact of not having done preheating of the combustion air and not having used secondary air jets. The secondary combustion air preheating prevents the temperature reduction in the combustion chamber and the secondary air jets enhance the mixing of devolatilised gases and combustion air [41]. However, it is necessary to take into account that these tests, rather than to design an optimised stove, intended to simulate a low cost, easy to implement, measure to reduce emissions from residential wood combustion.

Some variability in emission factors was observed, which may derive from several factors. There is variation in the biomass composition, even within the same species, which can induce differences in gaseous emission factors. Combustion conditions and operation are also very important factors. For example, high rates of combustion result in increased emissions of unburned products, which can be induced by the low moisture content of the biofuel [17]. The distribution of biomass itself on the grate and degree of compaction can cause significant differences in emissions [45].

The $\mathrm{CO} / \mathrm{CO}_{2}$ ratio is a measure of the relative combustion efficiency in terms of conversion of the fuel. A high ratio reflects lower combustion efficiency. The typical ratio for flame combustion phase is less than 0.1 [29]. On average, the ratios obtained for all combustion experiments were below this value, which indicates that the flame combustion phase was dominant. The highest ratios were obtained for the tests with low load operation for both biofuels.

There is a clear relationship between $\mathrm{CO}$ and $\mathrm{CO}_{2}$ emission factors and combustion temperatures. Thus, $\mathrm{CO}$ emission factors increase with decreasing combustion temperatures, whilst the $\mathrm{CO}_{2}$ emission factors have an opposite behaviour, increasing with increasing combustion temperatures. The technology of combustion is therefore a key factor in the emissions of these compounds. Advanced combustion technologies allow the reduction of $\mathrm{CO}$, enhancing its oxidation to $\mathrm{CO}_{2}$. On the other hand, fireplaces, where there is a high combustion air inlet reducing combustion temperatures, originate high CO emission factors.

\section{3. $P M_{10}$ emission factors}

The emission factors were calculated following the methodology described by Calvo et al. [28], taking into account the concentration of $\mathrm{PM}_{10}$ in the dilution tunnel, the mean combustion gas flow rate also in the dilution tunnel, the sampling time and the fuel mass consumed (dry basis). The emission factors for "softwood" combustion ranged between $5.07 \pm 0.30$ and $16.74 \pm 1.92$ ( $\mathrm{g} \mathrm{kg}^{-1}$ of wood burned, dry basis). With regard to the load and degree of cleavage, the lowest $\mathrm{PM}_{10}$ emission factor was observed when operating the stove with medium load, whilst the highest was generated when loading a lower amount of wood. The difference found was more than twice, as can be seen in Fig. 6. This difference is statistically significant $(p<0.0001)$. The $t$-test revealed that the difference found between the mean $\mathrm{PM}_{10}$ emission factors for medium and high loads (S and NS) was statistically significant ( $p=0.0121$ and $p=0.0004$, respectively). Too small chips and logs should only be used for the ignition. When small logs are used to feed the stove, the high devolatilisation rate leads to oxygen deficiency, causing high pollutant emissions [46]. Overall, non-split wood generates higher emissions than split wood. The start-up emissions can be substantial, since the temperatures in combustion chamber are reduced and the combustion rate is low, leading to a high PM emission factor. The duration of this step depends largely on the fuel properties, such as moisture content, density and size [47]. It could be verified that the use of big logs extends the initial combustion stage, contributing to higher PM emissions. The top-down ignition can reduce the $\mathrm{PM}_{10}$ emission factor to less than half when compared with the traditional technique. The differences between the mean $\mathrm{PM}_{10}$ emission factors for both lighting techniques are statistically significant $(p=0.0016)$. 


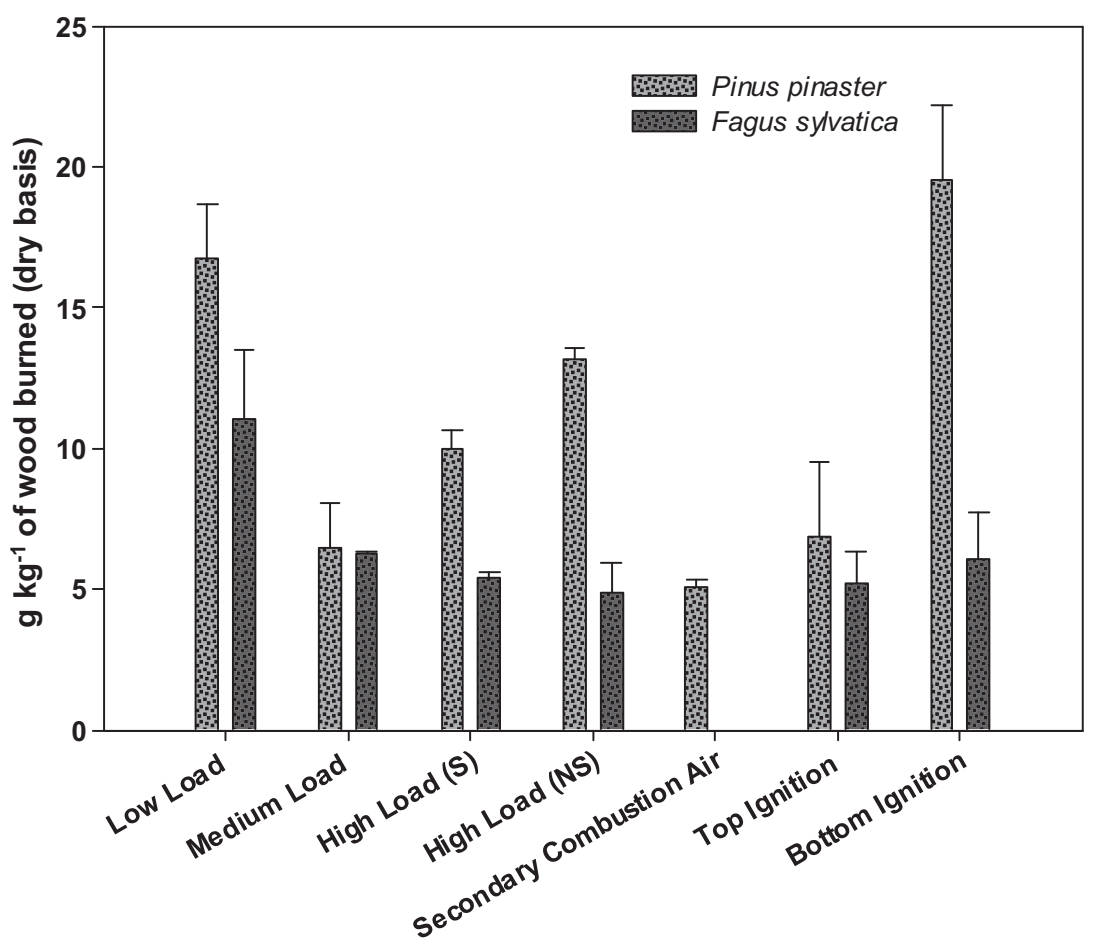

Fig. 6. Average and standard deviations of $\mathrm{PM}_{10}$ emission factors.

However, the difference between the mean $\mathrm{PM}_{10}$ emission factors for medium load (hot start) and top ignition (cold start) is not statistically significant ( $p=0.7986$ ). On the other hand, when the mean $\mathrm{PM}_{10}$ emission factor for medium load is compared with that of the bottom ignition technique the difference has shown to be statistically significant $(p<0.0001)$. The traditional ignition technique from the bottom causes the simultaneous firing of the entire batch of fuel, leading to high combustion rates and therefore oxygen deficit zones in the combustion chamber, which results in incomplete combustion. On the other hand, the top-down ignition promotes a gradual combustion of the fuel batch resulting in more complete combustion [48]. The use of a secondary combustion air flow was the operating condition that allowed obtaining the lowest $\mathrm{PM}_{10}$ emission factor. The soot and condensable organic matter can be reduced by staged combustion using primary air and a subsequent gas phase oxidation with secondary air [49].

$\mathrm{PM}_{10}$ emission factors obtained for beech combustion for each operating condition are presented in Fig. 6. The emission factors for this hardwood ranged from $4.86 \pm 1.06$ to $11.0 \pm 2.50\left(\mathrm{~g} \mathrm{~kg}^{-1}\right.$ of wood burned, dry basis) for the different loads tested. Contrary to what was observed for the softwood combustion, it seems that, except for low loads, the other operating conditions present similar emission factors. The differences between the means of $\mathrm{PM}_{10}$ emission factor for medium load were statistically significant when compared with the operation with low $(p=0.0300)$ and high load $(S)(p=0.0033)$. Compared to bottom lighting ( $6.06 \pm 1.65 \mathrm{~g} \mathrm{~kg}^{-1}$ of wood burned, dry basis), a slight reduction of the emission factor was observed when the ignition of the hardwood was carried out from the top $\left(5.24 \pm 1.10 \mathrm{~g} \mathrm{~kg}^{-1}\right.$ of wood burned, dry basis), but this difference was not statistically significant ( $p=0.4938$ ). As observed for the combustion of pine, the highest emission factors were generated under low load conditions. However, contrary to what was registered for the softwood combustion, the lowest emission factor was generated when operating under high loads without cleavage. The lower emission factor may be associated with a higher density of hardwood that promotes lower combustion rates compared to those observed for softwood. Hardwood burns slower and, thus, prevents the occurrence of oxygen deficit zones in the combustion chamber. The high temperatures recorded during operation with high loads, associated with good combustion air supply, promote a more efficient combustion [45]. Similarly to what was observed in this study for the hardwood tests, Schmidl et al. [24] found that combustion with "high fuel load" in a sophisticated stove presented lower $\mathrm{PM}_{10}$ emissions compared with the "normal" operation condition. The authors point out the reduced air combustion flow as a critical factor in particulate matter emissions. Some authors have already tried to assess the influence of the fuel load and oxygen supply on particulate emissions. Ozgen et al. [50] tested three closed manual appliances, namely a closed fireplace, a traditional stove, and an advanced stove. These appliances were tested to evaluate the influence of increased fuel load and decreased air through the application of two cycles (A and B). Both cycles comprised an ignition phase and three consecutive fuel loadings. The difference between cycles derived from the fact that, together with the complete closure of the primary air valve, the last fuel reloading in $A$ was 1.5 times higher than the nominal value in $B$. For the advanced stove, the authors observed a marked difference in the $\mathrm{PM}$ emissions between the two cycles. The difference in the average PM emissions was not so noticeable for the tests with the traditional stove and the closed fireplace. However, median values lower than mean values indicated the presence of very high emission factors during some test runs. In accordance with these results, Shen et al. [51] observed that under different feeding rates, PM, OC and EC emission factors were not statistically different. However, they noticed that PAH emission factors and their oxygenated and nitrated derivatives were much higher in the fast burning.

Tissari et al. [21] conducted tests on a conventional masonry heater in which two conditions have been tested, namely "normal combustion" and "smouldering combustion". The "smouldering combustion" conditions have been created using a high fuel load and by restricting the entry of combustion air. For normal combustion conditions the authors obtained an emission factor of $1.8 \pm 0.5 \mathrm{PM}_{1} \mathrm{~g} \mathrm{~kg}^{-1}$ of wood burned. For "smouldering combustion" conditions, the emission factor was about six times higher, with a mean value of $11.1 \pm 3.9 \mathrm{~g} \mathrm{~kg}^{-1}$. This value is identical to that obtained in this study under low load condition for beech combustion (11.0 $\mathrm{g} \mathrm{kg}^{-1}$ of wood burned, dry basis). Thus, reduced combustion temperatures, poor mixture between the 
flue gas and combustion air or short residence times contributed to increased emissions of particulate matter. The particle emission factors found in the literature may show great variability, due to the fuel characteristics, combustion equipment design, combustion conditions, dilution techniques and sampling procedures [21,22,32,42,52].

\subsection{Number emission factors}

The global number emission factors for each operating condition and for both fuels are presented in Table 3. With regard to the combustion of pine with different batch sizes, the maximum global emission factor was recorded when operating with low load $\left(1.05 \times 10^{17}\right.$ particles $\cdot \mathrm{kg}^{-1}$ biomass), whereas the minimum was registered when burning non-split logs in high load conditions $\left(4.08 \times 10^{16} \pm 3.48 \times 10^{15}\right.$ particles $\cdot \mathrm{kg}^{-1}$ of wood burned). The operation with secondary air originated a low emission factor $\left(2.19 \times 10^{16} \pm 1.50 \times 10^{15}\right.$ particles $\cdot \mathrm{kg}^{-1}$ of wood burned) compared with the emission factors mentioned above. Beech combustion showed the same trend described above. The overall maximum emission factor was observed when operating with low load $\left(1.09 \times 10^{17} \pm 1.08 \times 10^{16}\right.$ particles $\cdot \mathrm{kg}^{-1}$ of wood burned), whereas the minimum occurred under conditions of high load $(S)\left(2.47 \times 10^{16} \pm 6.09 \times 10^{14}\right.$ particles $\cdot \mathrm{kg}^{-1}$ of wood burned $)$.

Regarding the lightning technique, it can be seen that, for both woods, the overall emission factor is higher when the ignition is carried out from the top, although in the case of beech the difference between techniques is negligible. The top-down ignition technique generated emission factors between $5.26 \times 10^{16} \pm 1.15 \times 10^{16}$ and $3.68 \times 10^{16} \pm 2.54 \times 10^{15}$ (particles $\cdot \mathrm{kg}^{-1}$ of wood burned) for pine and beech, respectively. The bottom ignition technique contributed to emission factors between $5.72 \times 10^{15}$ and $3.69 \times 10^{16} \pm 2.33 \times 10^{15}$ (particles $\cdot \mathrm{kg}^{-1}$ of wood burned) for pine and beech, respectively. The top ignition leads to a progressive combustion of the fuel, resulting in more complete combustion, as described above. Thus, the increased combustion efficiency leads to number emission factors exceeding the number recorded for the traditional lighting technique, which originates incomplete combustion conditions. As observed for the PM emission factors, this trend is remarkably visible for the combustion of pine. The increase in the combustion temperature leads to the emission of a larger number of particles.

Tissari [8] observed that when the batch size was doubled in a conventional masonry heater, all emissions increased except the particle number emission. In our study, the same trend was verified in the combustion of pine. Using identical batches and modifying the size of the logs, Tissari [8] observed that the particle number emissions from small logs were 1.4-fold higher than from big logs. In the present study, for the same batch sizes, the number emission factor was higher when using logs without cleavage compared to the emission factor obtained with split logs.

Tissari et al. [22] studied the influence of the type of equipment and operating conditions on the particle number emission factors. The experiments involved the use of combustion appliances typically employed in Finland (conventional masonry stove and modern stove). Different biomass loads and log sizes were evaluated. The authors concluded that the number emission factor was higher for the modern combustion equipment $\left(5.9 \times 10^{14}\right.$ particles $\cdot \mathrm{kg}^{-1}$ of wood burned $)$ than that obtained with the conventional stove $\left(3.1 \times 10^{14}\right.$ particles $\cdot \mathrm{kg}^{-1}$ of wood burned). Moreover, the authors found that higher loads produce smaller number of particles $\left(2.0 \times 10^{14}\right.$ particles $\cdot \mathrm{kg}^{-1}$ biomass $)$ in comparison with low loads $\left(4.0 \times 10^{14}\right.$ particles $\cdot \mathrm{kg}^{-1}$ of wood burned $)$. This trend was also observed in the present study, although the recorded values are higher. The variations are probably related to differences in characteristics of combustion devices. When the degree of cleavage applied was higher, i.e. when smaller wood pieces were used, the authors found an increase in the number of particles $\left(3.1 \times 10^{14}\right.$ particles $\cdot \mathrm{kg}^{-1}$ of wood burned) comparatively to the number of particles emitted during the combustion of larger pieces of wood $\left(2.2 \times 10^{14}\right.$ particles $\cdot \mathrm{kg}^{-1}$ of wood burned) [20].

Tissari et al. [21] conducted tests on a conventional masonry stove. These tests comprised "normal combustion" and "smouldering combustion" conditions. The slow combustion conditions have been created using an excess of fuel load and restricting the entry of combustion air. The authors found that in improper combustion conditions (i.e. with excess of fuel and oxygen deficit in the combustion chamber), the number of particles was about 20\% lower compared to "normal" combustion conditions. The smaller number of particles occurs due to coagulation and condensation that contribute to the growth of the particles. Thus, the particle number is reduced and, moreover, size increases. The authors found that the mass emission was quite high due to the large sizes of particles emitted. Wardoyo [53] investigated the emissions of particles in a modified stove in order to allow the introduction of a controlled amount of air and variable combustion rates. The author tested "vigorous combustion" and "smouldering combustion" conditions. For the first condition a linear relationship $\left(R^{2}>0.93\right)$ between temperature and particle number concentration was found. The particle number for the "vigorous combustion" conditions ranged from 3.3 to $5.7 \times 10^{15}$ (particle $\cdot \mathrm{kg}^{-1}$ of wood burned). The "smouldering" conditions generated a lower number of particles (from 2.8 to $44.8 \times 10^{13}$ particles $\cdot \mathrm{kg}^{-1}$ of wood burned), as observed by Tissari et al. [21]. The tests performed in this study produced fewer particles for high load conditions with nonsplit logs, for which the combustion air supply is insufficient for high devolatilisation rates of biomass. Note that, for operation under low load, the PM mass emission factors were the highest among the tested conditions. As expected, these results were associated with unfavourable combustion conditions with reduced temperatures and low combustion rates. It should be taken into account, however, that the exact replication of conditions between successive combustion experiments is difficult, which causes variations in results.

\subsection{Aerosol size distributions}

Regarding the fuel load during pine combustion, the highest dg was registered in the operation with high load (NS) $(0.265 \pm 0.008 \mu \mathrm{m})$. The operation with secondary air supply generated the lowest $\operatorname{Dg}(0.153 \pm$ $0.000 \mu \mathrm{m}$ ) for the combustion of the coniferous wood. For beech combustion, the highest Dg was observed when operating the stove with high fuel load $(S)(0.243 \pm 0.046 \mu \mathrm{m})$.

Table 3

Mean geometric diameter $\left(D_{g}\right)$ and number emission factors (particles $\cdot \mathrm{kg}^{-1}$ of wood burned) for each operating condition (mean \pm standard deviation) for both fuels.

\begin{tabular}{|c|c|c|c|c|}
\hline & \multicolumn{2}{|l|}{ Fagus sylvatica } & \multicolumn{2}{|l|}{ Pinus pinaster } \\
\hline & $\mathrm{D}_{\mathrm{g}}(\mu \mathrm{m})$ & $\mathrm{EF}$ (particles $\cdot \mathrm{kg}^{-1}$ of wood burned) & $\mathrm{D}_{\mathrm{g}}(\mu \mathrm{m})$ & $\mathrm{EF}$ (particles $\cdot \mathrm{kg}^{-1}$ of wood burned) \\
\hline Low load & $0.205 \pm 0.016$ & $1.09 \mathrm{E}+17 \pm 1.08 \mathrm{E}+16$ & $0.175 \pm N A$ & $1.05 \mathrm{E}+17 \pm \mathrm{NA}$ \\
\hline Medium load & $0.234 \pm 0.011$ & $3.75 \mathrm{E}+16 \pm 9.87 \mathrm{E}+14$ & $0.175 \pm 0.037$ & $4.08 \mathrm{E}+16 \pm 1.29 \mathrm{E}+15$ \\
\hline High load (S) & $0.243 \pm 0.046$ & $2.47 \mathrm{E}+16 \pm 6.09 \mathrm{E}+14$ & NA & NA \\
\hline High load (NS) & $0.227 \pm 0.020$ & $3.09 \mathrm{E}+16 \pm 5.96 \mathrm{E}+15$ & $0.265 \pm 0.008$ & $4.08 \mathrm{E}+16 \pm 3.48 \mathrm{E}+15$ \\
\hline Secondary combustion air supply & $\mathrm{NA}$ & $\mathrm{NA}$ & $0.153 \pm 0,000$ & $2.19 \mathrm{E}+16 \pm 1.50 \mathrm{E}+15$ \\
\hline Top ignition & $0.165 \pm 0.001$ & $3.68 \mathrm{E}+16 \pm 2.54 \mathrm{E}+15$ & $0.149 \pm 0.016$ & $5.26 \mathrm{E}+16 \pm 1.15 \mathrm{E}+16$ \\
\hline Bottom ignition & $0.178 \pm 0.022$ & $3.69 \mathrm{E}+16 \pm 2.33 \mathrm{E}+15$ & $0.158 \pm N A$ & $5.72 \mathrm{E}+15 \pm \mathrm{NA}$ \\
\hline
\end{tabular}

NA - not applicable. 
With regard to the ignition technique, it has been found that, for pine combustion, the lowest Dg was recorded when using the top ignition technique $(0.149 \pm 0.016 \mu \mathrm{m})$. For beech combustion, the lowest Dg was observed when the ignition was performed from the top $(0.165 \pm 0.001 \mu \mathrm{m})$.

Particle size increases during conditions of incomplete combustion due to condensation and agglomeration processes induced by the low temperatures and poor mixing. Tissari et al. [22] found that modern biomass combustion equipment emits more particles, but smaller diameters. They also observed that the use of high biomass loads causes the increase of the particle diameter. This trend was also observed when using small pieces of wood. Pettersson et al. [17] concluded that the particulate material resulting from domestic combustion processes is dominated by submicron particles in the range from 0.1 to $0.3 \mu \mathrm{m}$. The researchers also found differences in the size distributions for the distinct stages of the combustion cycle. In this work, these trends were also observed. Conditions of incomplete combustion cause the formation of larger aggregates of soot and condensation of organic material into the pre-existing particles during the cooling of the exhaust effluent, modifying the particle diameters [17]. The increase of particle diameters under conditions of incomplete combustion was also observed by other authors. Tissari et al. [21] described a 2.5-fold increase in the geometric mean diameter for incomplete combustion conditions when comparing with "normal" combustion conditions.

The study of the temporal evolution of the number of particles in each channel has also been done. Analysing the operation with medium load (Fig. 7) it was observed a maximum number of $9.6 \times 10^{6}$ particles $\cdot \mathrm{cm}^{-3}$ for the size bin of $0.28 \mu \mathrm{m}$ during the first stage of the combustion cycle. Subsequently, there was a progressive decrease in the number of particles collected on the following channels. During the flaming stage, when the number of particles is at its maximum, a peak of $1.9 \times 10^{7}$ particles $\cdot \mathrm{cm}^{-3}$ for the size bin of $0.22 \mu \mathrm{m}$ was registered. During the flameless combustion stage, the peak, $7.1 \times 10^{7}$

a)

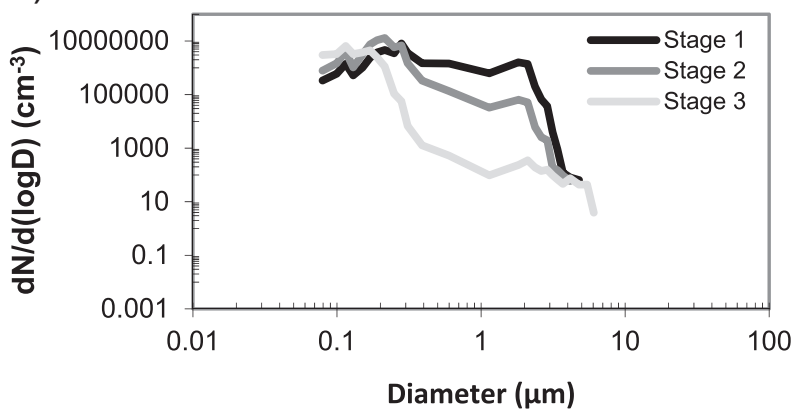

b)

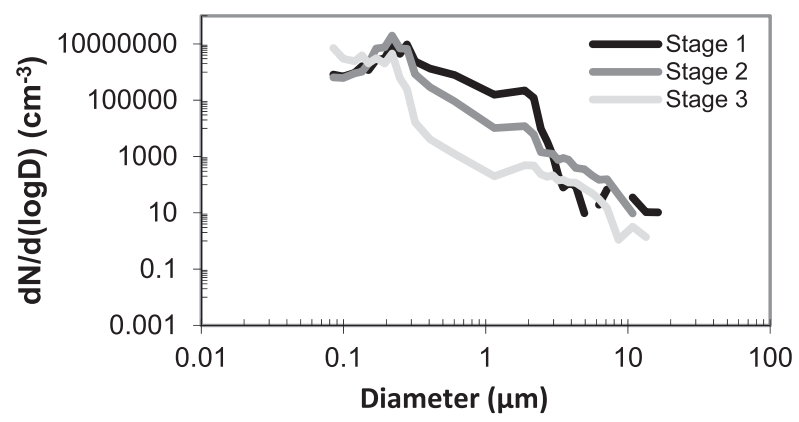

Fig. 7. Typical evolution of the distribution of the aerosol from the heating up combustion stage (stage 1) until the flameless combustion stage (stage 3 ) during the combustion of (a) beech combustion operating with medium load (b) pine combustion operating with medium load. particles $\cdot \mathrm{cm}^{-3}$, was recorded for the first channel $(0.08 \mu \mathrm{m})$. At this stage, the number of particles within the smallest size ranges experienced an increase compared with the values observed for phases 1 and 2. In the case of beech, the evolution of the number of particles is similar to that described above for pine combustion. In the first stage of the combustion cycle, a peak of $8.1 \times 10^{6}$ particles $\cdot \mathrm{cm}^{-3}$ in the size channel of $0.31 \mu \mathrm{m}$ was recorded. Thereafter, there is a progressive reduction in the number of particles. During the flaming phase, a maximum of $1.3 \times 10^{7}$ particles $\cdot \mathrm{cm}^{-3}$ in the size channel of $0.25 \mu \mathrm{m}$ was achieved. For flameless combustion, the largest number, $6.5 \times 10^{6}$ particles $\cdot \mathrm{cm}^{-3}$, was recorded for the third channel $(0.13 \mu \mathrm{m})$. At this stage, an increase in the number of particles within the smallest size bins is observed compared to the values of phases 1 and 2 .

\section{Conclusions}

The present work had as objective to experimentally characterise and quantify the gaseous and particulate emissions during combustion in a residential woodstove with variations in fuel and operating conditions. The comparison of values from this study with literature data showed differences, depending mainly on operating procedures and combustion technologies. Thus, to implement measures and as a guideline for future regulations, emission factors from different types of combustion devices under different operation modes are needed. This work may be potentially useful because it provides some guidance on best practices for households and end-users in Southern European countries, where the combustion of wood in traditional appliances is becoming ever more common.

The analysis of the $\mathrm{CO}$ and THC evolution over a combustion cycle showed that the initial stage is critical from the point of view of unburnt compound emissions, due to the rapid devolatilisation of biomass in a short period of time. The lowest particle emissions were generated under operation with medium fuel loads, whereas the highest were achieved for low and high loads of pine and beech, respectively. The secondary air supply enables to slightly reduce the THC emission factor. Cleavage also demonstrated to play an important role. Particulate emissions increase with the decrease of the surface area of the logs. Regarding the ignition technique, it was observed that the top-down ignition technique can reduce the $\mathrm{PM}_{10}$ emission factor to less than half compared with the traditional technique. The highest particle number emission factors were generated for the combustion of low load of both fuels. The lowest number emission factors were observed when operating with high load (S), for the combustion of beech, and when using a secondary air supply, for the combustion of pine. The smallest global particle geometric mean diameters were reached under low fuel load operation for beech and during the use of secondary air supply for pine combustion. The use of high loads, with split and non-split logs, generated, for both woods, the highest global Dg. Regarding the ignition technique, the global geometric mean diameters were the lowest among all the conditions tested using both techniques.

In batch operation, the conditions are highly variable throughout the different combustion phases. The log size affected emissions more than did batch size. The present study showed that a large variation in emissions can easily be achieved by the woodstove operators. Among all the conditions tested, it was possible to conclude that the ignition technique and combustion air supply are the operational parameters that most noticeably affect $\mathrm{PM}_{10}$ emissions.

\section{Acknowledgements}

This work was financially supported by AIRUSE - Testing and development of air quality mitigation measures in Southern Europe, LIFE 11 ENV/ES/000584. 


\section{References}

[1] A.A. Khan, W. de Jong, P.J. Jansens, H. Spliethoff, Biomass combustion in fluidized bed boilers: potential problems and remedies, Fuel Processing Technology 90 (2009) 21-50.

[2] R. Saidur, E.A. Abdelaziz, A. Demirbas, M.S. Hossain, S. Mekhilef, A review on biomass as a fuel for boilers, Renewable and Sustainable Energy Reviews 15 (2011) 2262-2289.

[3] C. Borrego, J. Valente, A. Carvalho, E. Sá, M. Lopes, A.I. Miranda, Contribution of residential wood combustion to PM10 levels in Portugal, Atmospheric Environment 44 (2010) 642-651.

[4] C. Gonçalves, C. Alves, C. Pio, Inventory of fine particulate organic compound emissions from residential wood combustion in Portugal, Atmospheric Environment 50 (2012) 297-306.

[5] H. Puxbaum, A. Caseiro, A. Sanchez-Ochoa, A. Kasper-Giebl, M. Clayes, A. Gelencser, M. Legrand, S. Preunkert, C. Pio, Levoglucosan levels at background sites in Europe for assessing the impact of biomass combustion on the European aerosol background, Journal of Geophysical Research 112 (2007) (D23S05/1-D23S05/11).

[6] A. Gelencsér, B. May, D. Simpson, A. Sánchez-Ochoa, A. Kasper-Giebl, H. Puxbaum, A. Caseiro, C. Pio, M. Legrand, Source apportionment of $\mathrm{PM}_{2.5}$ organic aerosol over Europe: primary/secondary, natural/anthropogenic, and fossil/biogenic origin, Journal of Geophysical Research 112 (2007) D23S04.

[7] M. Glasius, M. Ketzel, P. Wahlin, B. Jensen, J. Monster, R. Berkowicz, F. Palmgren, Impact of wood combustion on particle levels in a residential area in Denmark, Atmospheric Environment 40 (2006) 7115-7124

[8] J.Tissari, Fine particle emissions from residential wood combustion(PhD Thesis) Kuopio University Publications C. Natural and Environmental Sciences, Finland, 2008.

[9] A.K. Bølling, J. Pagels, K.E. Yttri, L. Barregard, G. Sallsten, P.E. Schwarze, C. Boman, Health effects of residential wood smoke particles: the importance of combustion conditions and physicochemical particle properties, Particle and Fibre Toxicology 6 (2009).

[10] J. Nevalainen, J. Pekkanen, The effect of particulate air pollution on life expectancy, Science of the Total Environment 217 (1998) 137-141.

[11] J.P. McCracken, G.A. Wellenius, G.S. Bloomfield, R.D. Brook, H.E. Tolunay, D.W. Dockery, C. Rabadan-Diehl, W. Checkley, S. Rajagopalan, Household air pollution from solid fuel use, Global Heart 7 (2012) 223-234.

[12] O. Uski, P.I. Jalava, M.S. Happo, J. Leskinen, O. Sippula, J. Tissari, J. Mäki-Paakkanen, J. Jokiniemi, M.-R. Hirvonen, Different toxic mechanisms are activated by emission PM depending on combustion efficiency, Atmospheric Environment 89 (2014) 623-632.

[13] T. Kaivosoja, P.I. Jalava, H. Lamberg, A. Virén, M. Tapanainen, T. Torvela, U. Tapper, O. Sippula, J. Tissari, R. Hillamo, M.-R. Hirvonen, J. Jokiniemi, Comparison of emissions and toxicological properties of fine particles from wood and oil boilers in small (20-25 kW) and medium (5-10 MW) scale, Atmospheric Environment 77 (2013) 193-201.

[14] B. Vu, C.A. Alves, C. Gonçalves, C. Pio, F. Gonçalves, R. Pereira, Mutagenicity assessment of aerosols in emissions from wood combustion in Portugal, Environmental Pollution 166 (2012) 172-181.

[15] L.P. Naeher, M. Brauer, M. Lipsett, J.T. Zelikoff, C.D. Simpson, J.Q. Koenig, K.R. Smith, Woodsmoke health effects: a review, Inhalation Toxicology 19 (2007) 67-106.

[16] J.T. Zelikoff, L.C. Chen, M.D. Cohen, R.B. Schlesinger, The toxicology of inhaled woodsmoke, Journal of Toxicology and Environmental Health Part B 5 (2002) 269-282.

[17] E. Pettersson, C. Boman, R. Westerholm, D. Boström, A. Nordin, Stove performance and emission characteristics in residential wood log and pellet combustion, part 2: wood stove, Energy \& Fuels 25 (2011) 315-323.

[18] W. Huang, T. Zhu, X. Pan, M. Hu, E.S. Lu, Y. Lin, Air pollution and autonomic and vascular dysfunction in patients with cardiovascular disease: interactions of systemic inflammation, overweight, and gender, American Journal of Epidemiology 176 (2012) 117-126.

[19] C. Alves, C. Gonçalves, A.P. Fernandes, L. Tarelho, C. Pio, Fireplace and woodstove fine particle emissions from combustion of western Mediterranean wood types, Atmospheric Environment 101 (2011) 692-700.

[20] C. Goncalves, C. Alves, M. Evtyugina, F. Mirante, C. Pio, A. Caseiro, C. Schmidl, H. Bauer, F. Carvalho, Characterisation of $\mathrm{PM}_{10}$ emissions from woodstove combustion of common woods grown in Portugal, Atmospheric Environment 44 (2010) 4474-4480.

[21] J. Tissari, J. Lyyränen, K. Hytönen, O. Sippula, U. Tapper, A. Frey, K. Saarnio, A.S. Pennanen, R. Hillamo, R.O. Salonen, M.-R. Hirvonen, J. Jokiniemi, Fine particle and gaseous emissions from normal and smouldering wood combustion in a conventional masonry heater, Atmospheric Environment 42 (2008) 7862-7873.

[22] J. Tissari, K. Hytönen, O. Sippula, J. Jokiniemi, The effects of operating conditions on emissions from masonry heaters and sauna stoves, Biomass and Bioenergy 33 (2009) 513-520.

[23] L.S. Johansson, B. Leckner, L. Gustavsson, D. Cooper, C. Tullin, A. Potter, Emission characteristics of modern and old-type residential boilers fired with wood logs and wood pellets, Atmospheric Environment 38 (2004) 4183-4195.

[24] C. Schmidl, M. Luisser, E. Padouvas, L. Lasselsberger, M. Rzaca, C. Ramirez-Santa Cruz, M. Handler, G. Peng, H. Bauer, H. Puxbaum, Particulate and gaseous emissions from manually and automatically fired small scale combustion systems, Atmospheric Environment 45 (2011) 7443-7454.

[25] L.S. Johansson, C. Tullin, B. Leckner, P. Sjövall, Particle emissions from biomass combustion in small combustors, Biomass and Bioenergy 25 (2003) 435-446.

[26] P.M. Fine, G.R. Cass, B.R. Simoneit, Chemical characterization of fine particle emissions from fireplace combustion of woods grown in the northeastern United States, Environmental Science and Technology 35 (2001) 2665-2675.

[27] J. Leskinen, J. Tissari, O. Uski, A. Virén, T. Torvela, T. Kaivosoja, H. Lamberg, I. Nuutinen, T. Kettunen, J. Joutsensaari, P.I. Jalava, O. Sippula, M.-R. Hirvonen, J. Jokiniemi, Fine particle emissions in three different combustion conditions of a wood chip-fired appliance - particulate physico-chemical properties and induced cell death, Atmospheric Environment 86 (2014) 129-139.

[28] A.I. Calvo, L.A.C. Tarelho, C.A. Alves, M. Duarte, T. Nunes, Characterization of operating conditions of two residential wood combustion appliances, Fuel Processing Technology 126 (2014) 222-232.

[29] A.P. Fernandes, C.A. Alves, C. Gonçalves, L. Tarelho, C. Pio, C. Schimdl, H. Bauer, Emission factors from residential combustion appliances burning Portuguese biomass fuels, Journal of Environmental Monitoring 13 (2011) 3196-3206.

[30] J.D. McDonald, B. Zielinska, E.M. Fujita, J.C. Sagebiel, J.C. Chow, J.G. Watson, Fine particle and gaseous emission rates from residential wood combustion, Environmental Science \& Technology 34 (2000) 2080-2091.

[31] J.J. Schauer, M.J. Kleeman, G.R. Cass, B.R.T. Simoneit, Measurement of emissions from air organic compounds from fireplace combustion of wood, Environmental Science \& Technology 35 (2001) 1716-1728.

[32] P.M. Fine, G.R. Cass, B.R.T. Simoneit, Chemical characterization of fine particle emissions from the wood stove combustion of prevalent United States tree species, Environmental Engineering Science 21 (2004) 705-721.

33] E. Hedberg, A. Kristensson, M. Ohlsson, C. Johansson, P. Johansson, E. Swietlicki, V. Vesely, U. Wideqvist, R. Westerholm, Chemical and physical characterization of emissions from birch wood combustion in a wood stove, Atmospheric Environment 36 (2002) 4823-4837.

[34] L.A.C. Tarelho, A.I. Calvo, D.S.F. Neves, C.A. Alves, M.A.A. Matos, Characteristics of wood combustion in a Portuguese fireplace and stove, Proceedings of the 19th European Biomass Conference and Exhibition, Berlin, Germany, 2011.

[35] A. Gelencsér, Carbonaceous Aerosol, Atmospheric and Oceanographic Science Library Series, vol. 30, Springer, New York, 2004.

[36] A.I. Calvo, V. Pont, A. Castro, M. Mallet, C. Palencia, J.C. Roger, P. Dubuisson, R. Fraile, Radiative forcing of haze during a forest fire in Spain, Journal of Geophysical Research 115 (2010) D08206.

[37] O. Dubovik, B. Holben, T.F. Eck, A. Smirnov, Y.J. Kaufman, M.D. King, D. Tanré, I Slutsker, Variability of absorption and optical properties of key aerosol types observed in worldwide locations, Journal of the Atmospheric Sciences 59 (2002) 590-608.

[38] A.A. Riziq, C. Erlick, E. Dinar, Y. Rudich, Optical properties of absorbing and nonabsorbing aerosols retrieved by Cavity Ring Down (CRD) spectroscopy, Atmospheric Chemistry and Physics 7 (2007) 1523-1536.

[39] E.J.T. Levin, G.R. McMeeking, C.M. Carrico, L.E. Mack, S.M. Kreidenweis, C.E. Wold, H Moosmüller, W.P. Arnott, W.M. Hao, J.L. Collett, W.C. Malm, Biomass burning smoke aerosol properties measured during Fire Laboratory at Missoula Experiments (FLAME), Journal of Geophysical Research 115 (2010) D18210.

[40] K. Hytönen, J. Jokiniemi (Eds.), Reduction of Fine Particle Emissions From Residential Wood Combustion, Workshop, Kuopio, Finland, 2006.

[41] T. Brunner, I. Obermberger, R. Scharler, Primary measures for low-emissions residential wood combustion - comparison of old with optimised modern systems, in: ETA-Renewable Energies (Ed.), 17th European Biomass Conference \& Exhibition, Hamburg, Germany, 2009.

[42] T. Nussbaumer, C. Czasch, N. Klippel, L. Johansson, C. Tullin, Particle emissions from biomass combustion in IEA countries, IEA Bioenergy Task 32, Zurich, 2008, ISBN 3908705-18-5.

[43] M. Evtyugina, C. Alves, A. Calvo, T. Nunes, L. Tarelho, M. Duarte, S.O. Prozil, D.V. Evtuguin, C. Pio, VOC emissions from residential combustion of Southern and mid-European woods, Atmospheric Environment 83 (2014) 90-98.

[44] E.B. Amorim, J.A. Carvalho, T.G. Soares Neto, E. Anselmo, V.O. Saito, F.F. Dias, J.C. Santos, Influence of specimen size, tray inclination and air flow rate on the emission of gases from biomass combustion, Atmospheric Environment 74 (2013) 52-59.

[45] J.J. Todd, Wood-Smoke Handbook: Woodheaters, Firewood and Operator Practice, Environment Australia and NSW Environment Protection Authority, Canberra, 2003.

[46] H. Hartmann, P. Turowski, I. Obernberger, F. Biedermann, T. Brunner, Low emission operation manual for chimney stove users, Report within the scope of the ERA-NET Bioenergy Project FutureBioTec, Graz, Austria, 2012.

[47] R. Koppmann, K. von Czapiewski, J.S. Reid, A review of biomass burning emissions, part I: gaseous emissions of carbon monoxide, methane, volatile organic compounds, and nitrogen containing compounds, Atmospheric Chemistry and Physics Discussions 5 (2005) 10455-10516.

[48] T. Nussbaumer, A. Doberer, N. Klippel, R. Bühler, W. Vock, Influence of ignition and operation type on particle emissions from residential wood combustion, Proceedings of the 16th European Biomass Conference and Exhibition, Valencia, Spain, 2008

[49] T. Nussbaumer, Biomass Combustion in Europe - Overview on Technologies and Regulations, NYSERDA, New York, 2008.

[50] S. Ozgen, S. Caserini, S. Galante, M. Giugliano, E. Angelino, A. Marongiu, F. Hugony, G. Migliavacca, C. Morreale, Emission factors from small scale appliances burning wood and pellets, Atmospheric Environment 94 (2014) 144-153.

[51] G. Shen, M. Xue, S. Wei, Y. Chen, Q. Zhao, B. Li, H. Wu, S. Tao, Influence of fuel moisture, charge size, feeding rate and air ventilation conditions on the emissions of PM, OC, EC, parent PAHs, and their derivatives from residential wood combustion, Journal of Environmental Sciences 25 (2013) 1808-1816.

[52] E.M. Lipsky, A.L. Robinson, Effects of dilution on fine particle mass and partitioning of semivolatile organics in diesel exhaust and wood smoke, Environmental Science \& Technology 40 (2006) 155-162.

[53] A.Y.P. Wardoyo, The relation of ultrafine particle emission production to temperature from wood burning, International Journal of Engineering Science and Innovative Technology (IJESIT) 1 (2012) 161-169. 